Full length article

\title{
Effect of laser remelting on microstructure and properties of WC reinforced Fe-based amorphous composite coatings by laser cladding
}

\author{
Shengfeng Zhou ${ }^{a}$, Yongbo Xu ${ }^{a}$, Bangquan Liao ${ }^{a}$, Yajuan Sun ${ }^{a}$, Xiaoqin Dai ${ }^{\text {a,* }}$, Jiaoxi Yang ${ }^{\mathrm{b}, *}$, \\ Zhengyang $\mathrm{Li}^{\mathrm{c}, *}$
}

a Laser Technology Institute, Tianjin Polytechnic University, Tianjin 300387, PR China

${ }^{\mathrm{b}}$ Institute of Laser Engineering, Beijing University of Technology, Beijing 100124, PR China

${ }^{\mathrm{c}}$ Institute of Mechanics, Chinese Academy of Sciences, Beijing 10090, PR China

\section{A R T I C L E I N F O}

\section{Article history:}

Received 6 November 2017

Received in revised form 5 December 2017

Accepted 5 January 2018

Available online 11 January 2018

\section{Keywords}

Amorphous composite

Laser cladding

Microstructure

Laser remelting

Corrosion

\begin{abstract}
A B S T R A C T
The WC reinforced Fe-based amorphous composite coatings were prepared by laser cladding with rectangular spot. The effect of laser remelting on the microstructure and properties of composite coatings was investigated. The results showed that laser remelting can reduce the cracks and porosities of the cladding coating and improve its surface quality. Large amounts of crystalline phases were precipitated at the top of the cladding and remelting coatings. However, the microstructure at the top of the remelting coating was finer compared to that at the top of the cladding coating. With increasing distance from the surface of substrate, the amorphous phase appeared within the remelting coating and large amounts of carbides rich in $\mathrm{Fe}$ and $\mathrm{Mo}, \mathrm{Fe}_{23} \mathrm{~B}_{6}, \gamma$-Fe and $\mathrm{Cr}_{9.1} \mathrm{Si}_{0.9}$ phases were also precipitated in the remelting coating. As a result, the corrosion resistance of the remelting coating was higher than that of the cladding coating. The microhardness of the remelting coating was approximately 1.13 times higher than that of the cladding coating.
\end{abstract}

(c) 2018 Elsevier Ltd. All rights reserved.

\section{Introduction}

Amorphous alloys, also known as metallic glasses, are metastable products obtained by rapid cooling [1]. Since Kramer et al. [2] and Brenner et al. [3] prepared amorphous Sb film and Ni-P amorphous film by vapor deposition and electrodeposition, respectively, many researchers have begun to produce metallic glasses by different methods. For instance, Duwez et al. [4] prepared $\mathrm{Au}_{70} \mathrm{Si}_{30}$ amorphous alloy by liquid spray quenching in 1960. Chen et al. [5] used rapid continuous casting roller to prepare lots of amorphous ribbons which were formally named as "metallic glass". In addition, mechanical alloying [6-8], melt spinning [9] and casting methods $[10,11]$ were also widely used to prepare metallic glasses. However, there were few reports that amorphous alloys have be used as structural materials due to limits of the glass forming ability (GFA) and inherent brittleness. In order to solve this problem, Miura et al. [12] prepared a series of FeNiP(Si)B amorphous coatings by flame spraying in 1984. Subsequently, amorphous coatings were produced widely by surface modification techniques, such as

\footnotetext{
* Corresponding authors.

E-mail addresses: daixq0827@163.com (X. Dai), yangjiaoxi@bjut.edu.cn (J. Yang), zyli@imech.ac.cn (Z. Li).
}

plasma spraying [13,14], HVOF [15,16] and laser cladding [17-19]. These amorphous coatings exhibit many excellent properties, such as high hardness, high tensile strength, good wear and corrosion resistance and excellent magnetic properties [20-22].

Compared to the traditional thermal spraying techniques, laser cladding is characterized by high power density $\left(10^{4}-10^{6} \mathrm{~W} / \mathrm{cm}^{2}\right)$, rapid cooling rate $\left(10^{4}-10^{6} \mathrm{~K} / \mathrm{s}\right)$, and can produce dense coatings with low dilution and metallurgical bonding to substrate [23]. Therefore, it has become a prospective technique to prepare amorphous coatings with high properties. For example, Yoshioka et al. [24] prepared amorphous Ni-Cr-P-B coating on the surface of low carbon steel by laser cladding, the result showed that when the chemical composition including $\mathrm{Cr}$ in $14-17$ at.\%, $\mathrm{P}$ in $15-18$ at.\%, $\mathrm{B}$ in $2-5$ at.\%, B and $\mathrm{P}$ in 19-20 at.\% was designed, a amorphous coating can be obtained successfully. Wu et al. [25] prepared Febased amorphous coating with a thickness of $1.2 \mathrm{~mm}$ by laser cladding, and found that the amorphous coating exhibited high microhardness and corrosion resistance. Li et al. [26] prepared Ni-Fe-B$\mathrm{Si}$-Nb amorphous coatings by laser cladding and found that amorphous phase did not form when the laser power was $1 \mathrm{~kW}$. However, when the laser power was less than $1 \mathrm{~kW}(0.7-0.9 \mathrm{~kW})$, amorphous phase appeared and resulted in an improvement in microhardness of coating. 
In order to further improve the performance of amorphous coatings, the particle reinforced amorphous composite coatings prepared by plasma spraying, HVOF or laser cladding have received significant attention. For instance, Xu et al. [27] prepared stainless steel reinforced Fe-based amorphous composite coating by HVOF. The results indicated that the pitting of composite coating in $3.5 \% \mathrm{NaCl}$ solution was attributed to the formation of oxide $\left(\mathrm{Fe}_{3} \mathrm{O}_{4}\right)$ at the interfaces. Yoon et al. [28] prepared $\mathrm{B}_{4} \mathrm{C}$ reinforced Fe-based amorphous composite coatings by plasma spraying, and found that the microhardness and wear resistance of the composite coatings were improved significantly. Yue et al. [29] prepared $\mathrm{SiC}$ reinforced $\mathrm{Zr}$-based amorphous composite coatings by laser cladding. The results showed that $\mathrm{SiC}$ addition could enhance the microhardness and wear resistance, but the corrosion resistance of amorphous composite coatings was reduced. In addition, laser remelting was considered as an effective method to improve the surface quality and properties of cladding coating. It has been extensively adopted to prepare the amorphous coatings with dense structure and excellent properties [30-33]. However, to the authors' knowledge, the research of combining laser cladding with laser remelting to prepare WC reinforced amorphous composite coatings is rarely reported. In this paper, the combination of laser cladding and laser remelting is used to prepare WC reinforced Fe-based amorphous composite coatings, and the emphasis is to comparatively investigate the microstructure and corrosion resistance of composite coatings.

\section{Experimental procedures}

\subsection{Materials}

In this experiment, 45 steel $(0.45 \mathrm{wt} . \% \mathrm{C})$ with dimensions of 60 $\times 40 \times 10 \mathrm{~mm}^{3}$ was used as the substrate and its chemical composition was listed in Table 1 . The mixture of Fe-based amorphous powder with a size of $15-50 \mu \mathrm{m}$ and WC particles with a size of $15-25 \mu \mathrm{m}$ at a mass ratio of 9:1 was used as the cladding material. The chemical composition of the Fe-based amorphous powder was listed in Table 2 and its X-ray diffraction (XRD) pattern was shown in Fig. 1.

\subsection{Laser cladding and laser remelting}

Before laser cladding, the cladding material was pre-placed on the substrate to form a powder bed with a thickness of $\sim 1.2 \mathrm{~mm}$ and a width of $\sim 14 \mathrm{~mm}$. The experiment of laser cladding and laser remelting was carried out using a $8 \mathrm{~kW}$ semiconductor laser with a wavelength of $980 \mathrm{~nm}$. The processing parameters of laser cladding and laser remelting were listed in Table 3.

\subsection{Microstructure and properties}

The geometrical profiles of the composite coatings were analyzed by optical microscopy (OM). Phase constituents were analyzed by D/MAX-2500 X-ray diffraction (XRD, target: $\mathrm{Cu}, 40 \mathrm{kV}$, $40 \mathrm{~mA}$ ). Microstructure was characterized by ZEISS Sigma 300 field emission scanning electron microscopy (SEM) equipped with energy dispersive spectrometer (EDS).

Electrochemical measurements were carried out in $3.5 \mathrm{NaCl}$ solution with an electrochemical workstation (CHI 660C, Shanghai, China). The device with a conventional three-electrode cell, which was composed of a working electrode (WE) made from the coating specimen with an exposed area of $0.58 \mathrm{~cm}^{2}$, a platinum counter electrode (CE), and a saturated calomel reference electrode (SCE) as reference electrode connected to a Luggin capillary bridge. The potentiodynamic polarization curves were recorded at a sweeping rate of $20 \mathrm{mV} \mathrm{min}^{-1}$, starting from the moment when the open circuit potential (OCP) reached its steady state after immersing the specimen in the electrolyte for about $1 \mathrm{~h}$. Meanwhile, electrochemical impedance spectroscopy (EIS) was performed at OCP potentiostatically at a frequency range from $10^{-2}-10^{5} \mathrm{~Hz}$. The equivalent circuits and corresponding Nyquist as well as Bode plots were fitted by impedance spectrum data using Zsimpwin software. All potentials mentioned in this work were measured with respect to saturated calomel electrode (SCE). Microhardness was measured by HV-1000 microhardness tester with a load of $0.98 \mathrm{~N}$ and a dwelling time of $15 \mathrm{~s}$.

\section{Results and discussion}

\subsection{Macro-profile of coatings}

Fig. 2 shows the geometrical morphology of WC reinforced Febased amorphous composite coatings before and after laser remelting. The cracks, pores and wavy appearance caused by convection in the molten pool can be seen on the surface of the cladding coating (Fig. 2a). Moreover, some spherical non-melted particles are observed on the surface and both sides of the cladding coating. Obviously, the surface quality of the cladding coating is not well. After laser remelting, the surface of the cladding coating becomes smooth and no cracks and pores are observed (Fig. 2b). Moreover, the width is reduced by $10.03 \%$ but the height is increased by $8.25 \%$ compared to the cladding coating with a width of $13.36 \mathrm{~mm}$ and a height of $0.97 \mathrm{~mm}$ (Fig. 2c). This is because the cladding coating is remelted to a liquid melt that is more prone to shrink due to minimization surface energy. Compared to laser cladding, the increasing of laser scanning speed during laser remelting can reduce the temperature of the melt and therefore increase its viscosity and surface tension, leading to an increase in cladding height. In addition, the non-melted particles on the surface and both sides of the cladding coating are also beneficial to an increase in cladding height after laser remelting.

\subsection{Microstructure of coatings}

Fig. 3 shows the XRD patterns at the top of the cladding and remelting coatings. The phase constituents of the cladding coating are composed of $\mathrm{M}_{23} \mathrm{C}_{6}\left(\mathrm{M}=\mathrm{Fe}, \mathrm{Cr}\right.$ ) with a cubic structure, $\mathrm{Fe}_{2} \mathrm{~B}$ with a tetragonal structure and $\mathrm{Fe}_{3} \mathrm{Mo}$ with a rhombohedral structure. Some scattering peaks appear at $2 \theta=44^{\circ}$ and $95^{\circ}$, indicating the presence of amorphous phase. After laser remelting, there are still $\mathrm{M}_{23} \mathrm{C}_{6}$ carbides in the coating, but $\mathrm{Fe}_{2} \mathrm{~B}$ and $\mathrm{Fe}_{3}$ Mo phases are melted to form the orthogonal $\mathrm{FeB}$ and cubic $\mathrm{Fe}_{9.7} \mathrm{Mo}_{0.3}$ phases. Meanwhile, large amounts of $\gamma-\mathrm{Fe}(\mathrm{Cr})$ and $\mathrm{Cr}_{9.1} \mathrm{Si}_{0.9}$ are formed and no evidently scattering peaks are observed at the top of the remelting coating, showing that some crystalline phases are remelted to form new phases after rapid solidification.

Fig. 4 shows the XRD patterns at the center of the cladding and remelting coatings. Obviously, compared to those at the top of the cladding and remelting coatings, the relative intensities of crystalline peaks are decreased and the wider diffraction peaks appear at $2 \theta=44^{\circ}, 75^{\circ}, 90^{\circ}$ and $115^{\circ}$ before and after laser remelting, indicating that the more amorphous phase appears at the center of the cladding and remelting coatings. Generally, the cooling rate decreased with increasing distance from the bottom of molten pool during laser cladding [23]. Therefore, the cooling rate at the center of the molten pool is readily to reach the critical cooling rate for the formation of amorphous phase so that the crystalline nucleation and growth are able to be suppressed, compared to that at the top of the molten pool. As a result, the diffraction peaks of amorphous phase at the center of the coatings are wider than those at 
Table 1

Chemical composition of substrate (wt.\%).

\begin{tabular}{|c|c|c|c|c|c|c|c|}
\hline $\mathrm{Mn}$ & $\mathrm{P}$ & C & $\mathrm{Si}$ & $S$ & $\mathrm{Ni}$ & $\mathrm{Cr}$ & $\mathrm{Fe}$ \\
\hline $0.5-0.8$ & $\leq 0.04$ & $0.42-0.50$ & $0.17-0.37$ & $\leq 0.04$ & $\leq 0.25$ & $\leq 0.25$ & Balance \\
\hline
\end{tabular}

Table 2

Chemical composition of Fe-based amorphous alloy powder (at.\%).

\begin{tabular}{|c|c|c|c|c|c|c|c|}
\hline Mn & Mo & W & $\mathrm{Si}$ & C & B & $\mathrm{Cr}$ & $\mathrm{Fe}$ \\
\hline 1.9 & 7.4 & 1.6 & 2.4 & 3.8 & 15.2 & 18 & Bal. \\
\hline
\end{tabular}

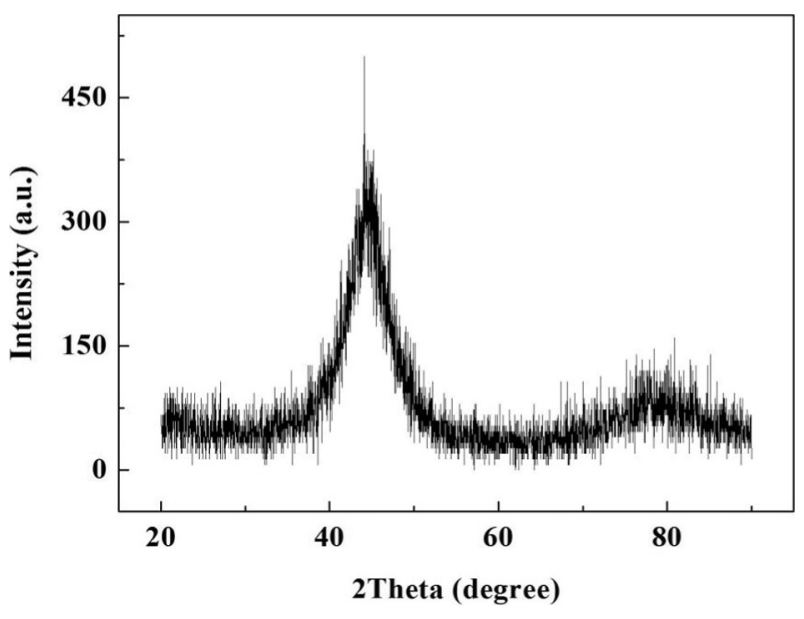

Fig. 1. XRD pattern of Fe-based amorphous powder.

Table 3

The processing parameters of laser cladding and laser remelting.

\begin{tabular}{llll}
\hline $\begin{array}{l}\text { Processing } \\
\text { mode }\end{array}$ & $\begin{array}{l}\text { Power } \\
(\mathrm{kW})\end{array}$ & $\begin{array}{l}\text { Scanning speed }(\mathrm{mm} / \\
\mathrm{s})\end{array}$ & $\begin{array}{l}\text { Spot dimension } \\
\left(\mathrm{mm}^{2}\right)\end{array}$ \\
\hline $\begin{array}{l}\text { Laser cladding } \\
\text { Laser remelting }\end{array}$ & 2.5 & 4 & $3 \times 12$ \\
& 4.5 & 20 & $3 \times 12$ \\
\hline
\end{tabular}

the top of the coating. Furthermore, when the laser scanning speed is increased to $20 \mathrm{~mm} / \mathrm{s}$ during rapid solidification, the diffraction peaks of the remelting coating become wider than those of the cladding coating, indicating that laser remelting is beneficial to the formation of amorphous phase as a result of higher cooling rate. Therefore, more amorphous phase can be obtained during laser remelting with higher laser scanning speed [34].

Fig. 5 shows the backscattered images of the microstructure at the top of the cladding and remelting coatings. The microstructure of the cladding coating is characterized by the coarse crystalline and a large number of irregular gray phase III (blue arrow marked in Fig. 5a). These crystalline phases dispersed independently within the gray phase III present the growth of equiaxed dendrites. However, the partial cladding coating can be remelted so that the atoms are rearranged and the relatively higher cooling rate can be induced as a result of increasing laser scanning speed during laser remelting $(20 \mathrm{~mm} / \mathrm{s})$. Thus, the irregular gray phase III is not seen clearly, whereas the very fine and dense microstructure is formed in the remelting coating (Fig. 5b), which is consistent with the results reported by Li [35].

Fig. 6 shows the backscattered images of the microstructure at the center of the cladding and remelting coatings. The equiaxed dendrites and some secondary dendrites are observed in the cladding coating (Fig. $6 \mathbf{a}$ and b). However, the equiaxed dendrites and primary dendrites are observed in the remelting cladding (Fig. $6 \mathrm{c}$ and d). Obviously, the amount of gray phase III is increased
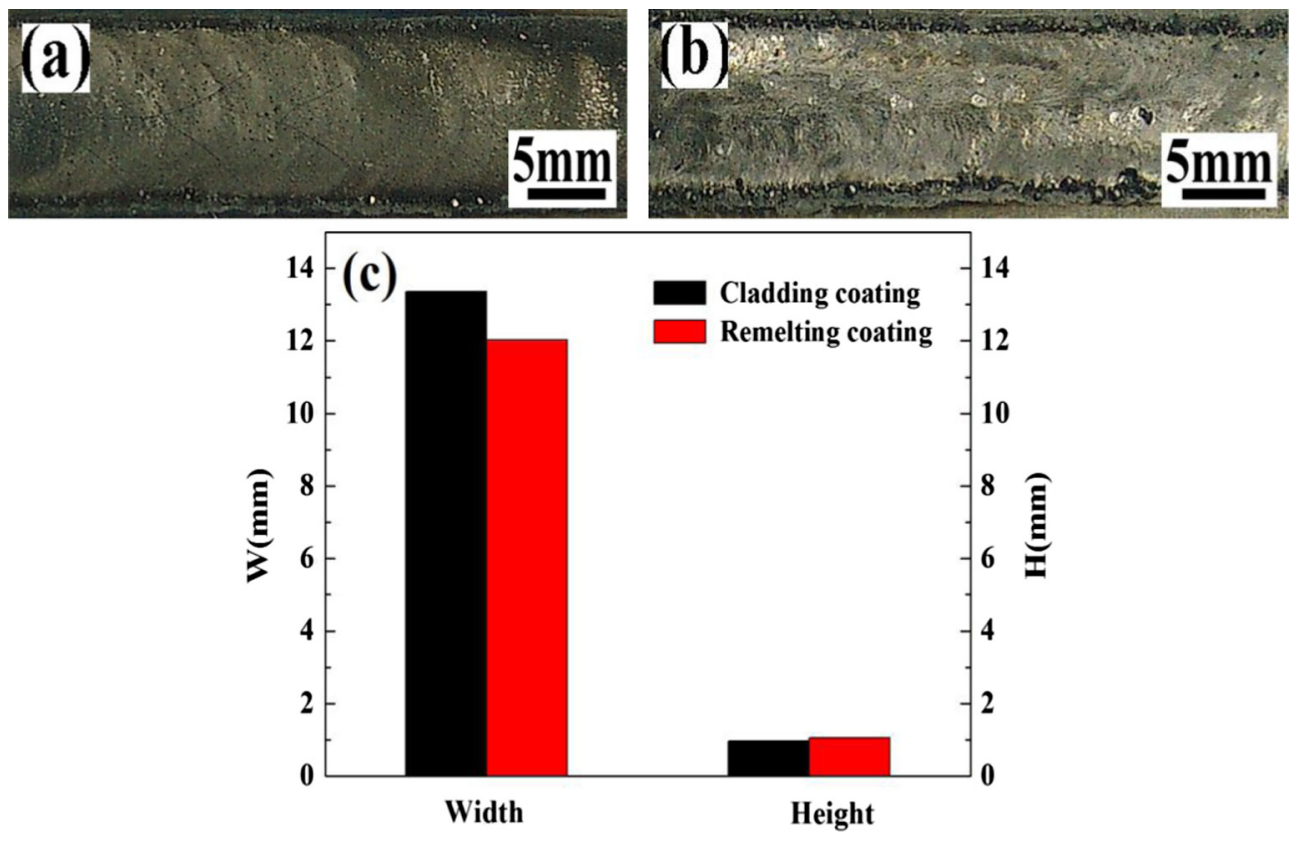

Fig. 2. Macro-appearance of Fe-based amorphous composite coatings: (a) cladding coating, (b) remelting coating, (c) geometrical profile. 


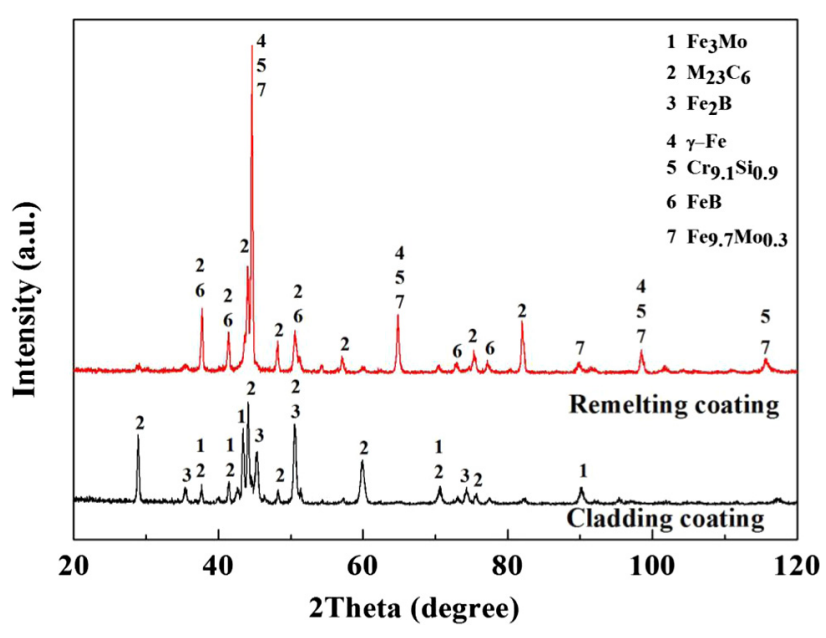

Fig. 3. XRD patterns at the top of Fe-based amorphous composite coatings.

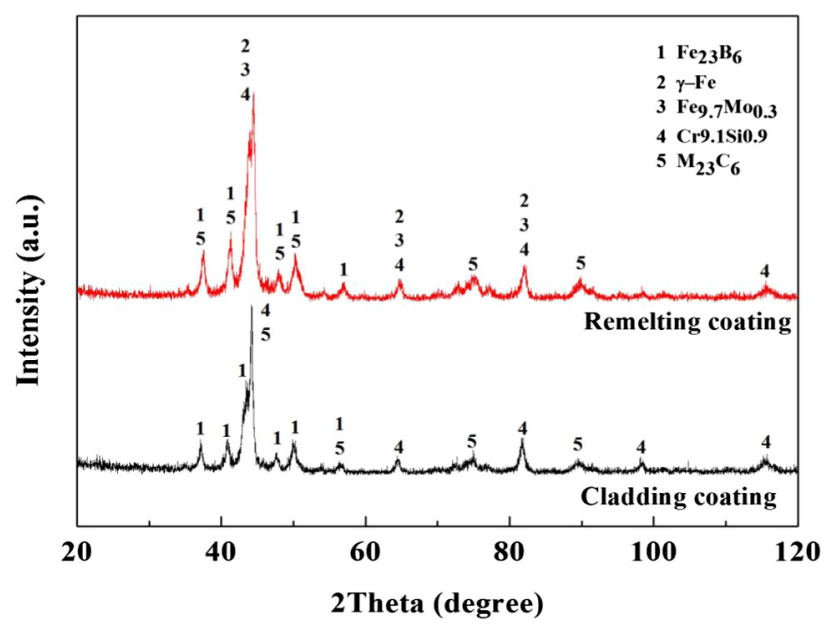

Fig. 4. XRD patterns at the center of Fe-based amorphous composite coatings.

significantly after laser remelting and the microstructure is finer and more homogeneous than that of the cladding coating.

Fig. 7 shows the backscattered images of the microstructure at the bottom of the cladding and remelting coatings. The cladding coating presents the planar growth with a thickness of $\sim 3 \mu \mathrm{m}$ (Fig. 7a and c). With increasing distance from the surface of substrate, the planar growth is suppressed and the columnar dendrites are formed. Subsequently, the columnar dendrites are inhibited because they can be affected by heat flow along the direction of heat flux, so the secondary dendrites $(\sim 60 \mu \mathrm{m})$ can be formed in the opposite direction of heat flow. Meanwhile, large amounts of white phases I (Red arrow in Fig. 7c) are observed at the coatingsubstrate interface. Comparatively, the dendrite arm spacing (DAS) of the black columnar phases II $(\sim 50 \mu \mathrm{m})$ in the remelting coating (yellow ${ }^{1}$ arrow in Fig. $\left.7 d\right)$ is much larger than that $(\sim 15$ $\mu \mathrm{m}$ ) in the cladding coating (yellow arrow in Fig. 7c). Obviously, the columnar dendrites are coarsened evidently at the bottom of the remelting coating. Moreover, many white phases I (red arrow in Fig. 7d) are precipitated not only at the bottom of the remelting coating, but also at the center of the remelting coating (white arrow in Fig. 6c).

${ }^{1}$ For interpretation of color in Fig. 7, the reader is referred to the web version of this article.
According to the theory of the rapid solidification [32,36,37], the microstructure characteristics are related to the ratio of temperature gradient $G$ to solidification rate $R$, i.e. $G / R$. When laser beam interacts with the pre-placed powder, the molten powder can transfer the partial heat to melt the surface of substrate, resulting in metallurgical bonding. Moreover, the $\mathrm{G}$ is the largest and the $\mathrm{R}$ is the smallest at the bottom of the molten pool, so that the ratio $G / R$ is nearly infinite. This in turn leads to the planar growth at the bottom of the composite coatings. Additionally, the supersaturated solid solution is formed (back phase II in Table 4) owing to the partial melting of the substrate. With increasing distance from the surface of substrate, the $G$ decreases and the $R$ increases, leading to a decrease in $\mathrm{G} / \mathrm{R}$. The solid/liquid interface is unstable, resulting in the growth of columnar dendrites in the coatings (Fig. 7a and b). When the cladding coating is remelted to form a molten pool, the $\mathrm{Fe}_{2} \mathrm{~B}$ and $\mathrm{Fe}_{3} \mathrm{Mo}$ phases are dissolved and atoms are rearranged to form $\mathrm{Fe}_{23} \mathrm{~B}_{6}$ and $\mathrm{Fe}_{9.7} \mathrm{Mo}_{0.3}$ phases. Furthermore, large amounts of $\gamma$-Fe and $\mathrm{Cr}_{9.1} \mathrm{Si}_{0.9}$ phases can be also precipitated from the amorphous matrix [32]. However, the bottom of cladding coating is unmelted completely due to higher laser scanning speed (20 $\mathrm{mm} / \mathrm{s}$ ) during laser remelting, resulting in the coarse dendrites. With further increasing distance from the surface of substrate, the heat removal of the molten pool is non-directional, leading to the formation of the equiaxed dendrites (Fig. 5). Compared to laser cladding, a higher laser scanning speed during laser remelting can obtain a higher cooling rate and a higher supercooling [38]. As a result, the finer microstructure of the remelting coating can be obtained at the center and top of the coating (Figs. 5 and 6).

As mentioned above, the white phase I is distributed within the interdendrites in the cladding coating (Fig. 7a and c) and remelting coating (Figs. $6 \mathrm{c}$ and $7 \mathrm{~b}$ ). According to the EDS spectrum, the white phase I contains large amounts of Fe, W, C and Mo atoms and small amounts of $\mathrm{Cr}$ and $\mathrm{Mn}$ atoms. Due to a low free formation enthalpy $(38.5 \mathrm{~kJ} / \mathrm{mol})$ [39], WC particles easily suffer from the dissolution in the molten Fe-based alloy. Babu et al. [40] estimated that the complete dissolution time of WC was about $0.055 \mathrm{~s}$ in the Febased alloy solvent during laser cladding by using ThermoCalc software. Therefore, the $\mathrm{C}$ and $\mathrm{W}$ atoms from the dissolution of WC particles can interact with Fe-based amorphous matrix or Feand Mo-rich phases to precipitate the (Fe, Mo)-rich carbides with a blocky morphology (Fig. 7c and d) and form new amorphous phase after rapid solidification. According to the results of XRD and EDS analysis (Figs. 3, 4 and Table 4), the irregular phase III can be identified as Fe-based amorphous matrix and the black phase II is solid solution rich in $\mathrm{Cr}$ and $\mathrm{Fe}$. The white phase I can be identified as carbides rich in Fe and Mo.

\subsection{Electrochemical corrosion of coatings}

Fig. 8 shows the potentiodynamic polarization curves of the cladding coating, remelting coating and substrate in $3.5 \mathrm{wt} . \% \mathrm{NaCl}$ solution. The parameters of electrochemical corrosion, i.e. corrosion potential $\left(\mathrm{E}_{\mathrm{corr}}\right)$, corrosion current density $\left(\mathrm{I}_{\mathrm{corr}}\right)$ and polarization resistance $R_{p}$, are listed in Table 5 . It is generally believed that the lower $\mathrm{I}_{\text {corr }}$ denotes the lower corrosion rate and the higher $\mathrm{E}_{\text {corr }}$ represents the lower corrosion thermodynamic tendency $[41,42]$. Compared to the cladding coating and substrate, the remelting coating has a relatively higher $\mathrm{E}_{\text {corr }}(-0.884 \mathrm{~V})$ and lower $\mathrm{I}_{\text {corr }}(1$. $25 \times 10^{-5} \mathrm{~A} / \mathrm{cm}^{2}$ ), indicating that the remelting coating has a relatively higher corrosion resistance. In addition, the $\mathrm{R}_{\mathrm{p}}$ of the remelting coating is relatively higher than that of the substrate and cladding coating, which further confirms that the remelting coating has a relatively lower corrosion rate. Obviously, laser remelting can improve the corrosion resistance of the cladding coating.

In order to further study the corrosion resistance of the cladding and remelting coatings in $3.5 \mathrm{wt} . \% \mathrm{NaCl}$ solution, the electrochem- 

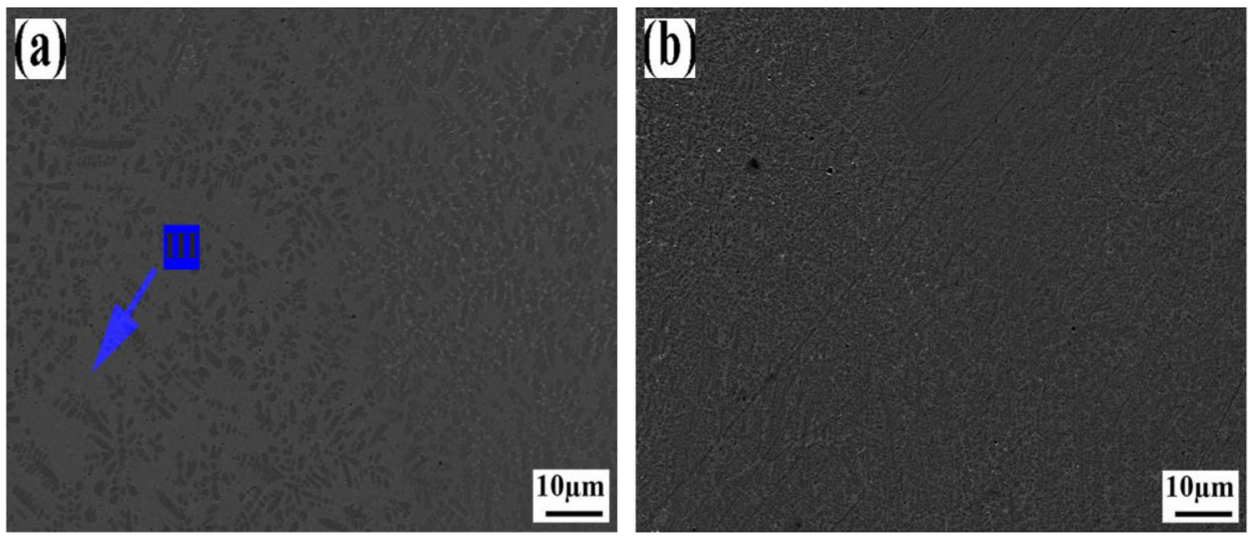

Fig. 5. Backscattered images of the microstructure at the top of Fe-based amorphous composite coatings: (a) cladding coating, (b) remelting coating.
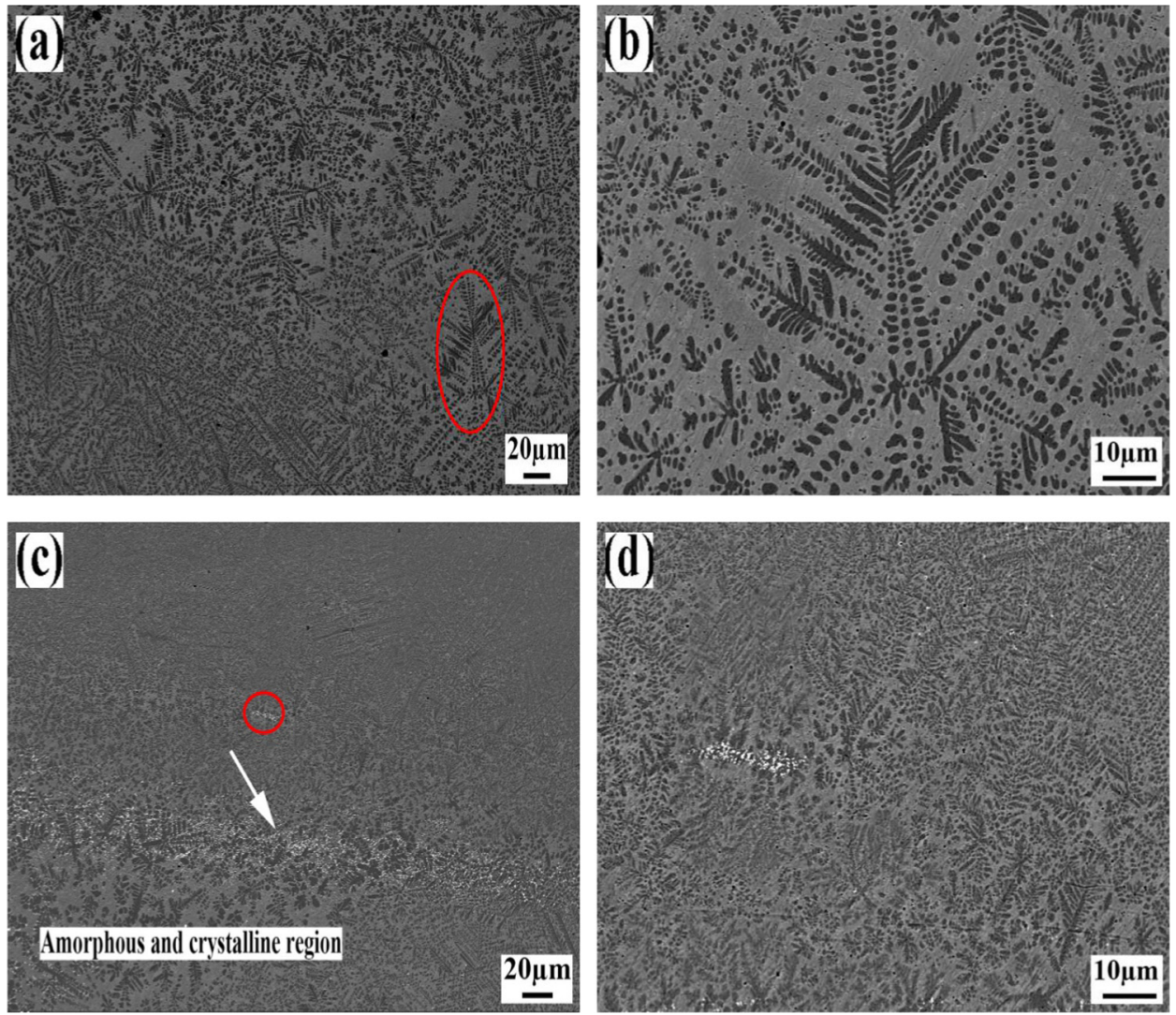

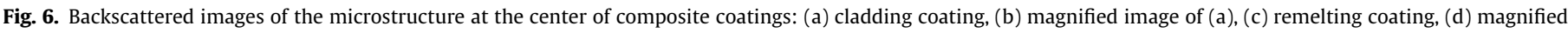
image of (c).

ical workstation is used to measure the EIS, i.e. the Nyquist patterns (Fig. 9) and the Bode patterns (Fig. 10), wherein the black solid line indicates the impedance spectrum obtained by fitting the equivalent circuits and the mark symbol represents the actually measured data in Fig. 10. It can be seen from Fig. 9 that the substrate exhibits only a complete capacitive arc in the whole frequency region, while the cladding and remelting coatings have two capacitive arcs (black and green arrows in Fig. 9), which can be further confirmed by their equivalent circuits (Fig. 11) and those equivalent circuits were also observed in literatures [43-45]. In order to obtain the optimal fitting results, the equivalent circuits chosen $\chi^{2}$ (chi-squared) must be in the $10^{-4}-10^{-3}$ and the results are listed in Table 6. Obviously, the cladding and remelting coat- ings have similar equivalent elements, such as the solution resistance $R_{s}$ consisted of reference electrode and working electrode, the coating resistance $R_{p}$ and the charge transfer resistance $R_{t}$. In addition, the equivalent circuit of the cladding coating includes an electric double layer capacitor $C$ and a constant phase angle $\mathrm{Q}_{1}$ composed of solution and coating, where $\mathrm{Q}_{1}$ represents a nonideal capacitance of the cladding coating and substrate caused by non-uniform electrode interface. The equivalent circuit of the remelting coating consists of two constant phase angles, i.e. $\mathrm{Q}_{1}$ consisting of solution and coating, and $\mathrm{Q}_{2}$ consisting of coating and substrate.

Although the Nyquist patterns of the cladding and remelting coatings have similar characteristics, the capacitive arc diameter 

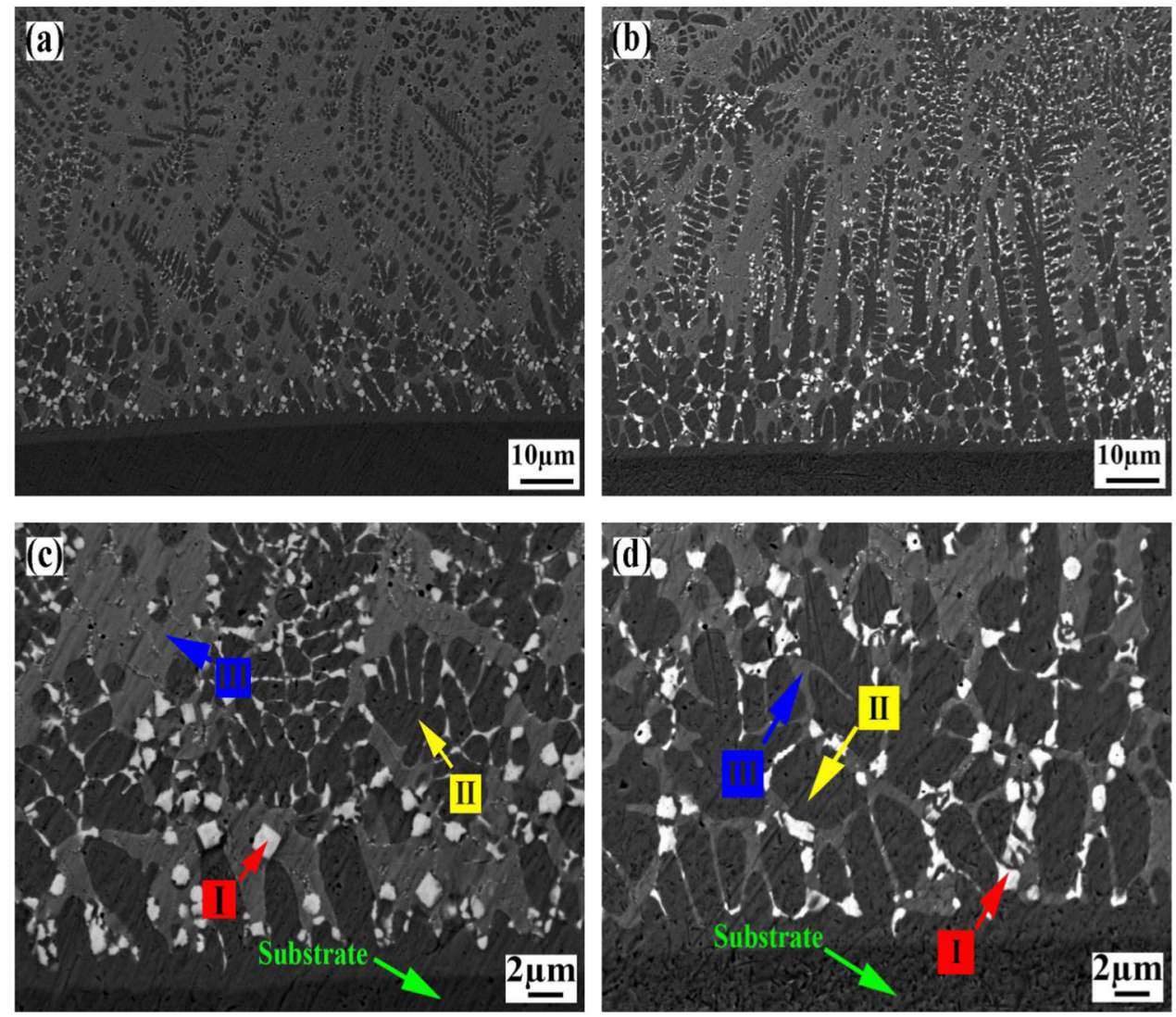

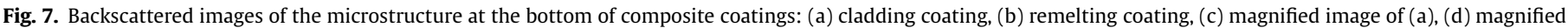
image of (b).

Table 4

EDS analysis of microstructure in WC reinforced Fe-based amorphous composite coatings.

\begin{tabular}{|c|c|c|c|c|c|c|c|}
\hline \multirow[t]{2}{*}{ Microstructure characteristics } & \multicolumn{7}{|c|}{ Composition (wt.\%) } \\
\hline & C & $\mathrm{Cr}$ & $\mathrm{Mn}$ & Mo & W & $\mathrm{Si}$ & $\mathrm{Fe}$ \\
\hline White phase I & 9.21 & 14.36 & 0.86 & 21.96 & 25.94 & - & 27.67 \\
\hline Black phase II & 8.13 & 7.70 & 1.83 & 2.15 & 3.18 & 0.87 & 76.14 \\
\hline Gray phase III & 11.5 & 14.76 & 1.93 & 8.33 & 8.45 & 0.02 & 55.05 \\
\hline
\end{tabular}

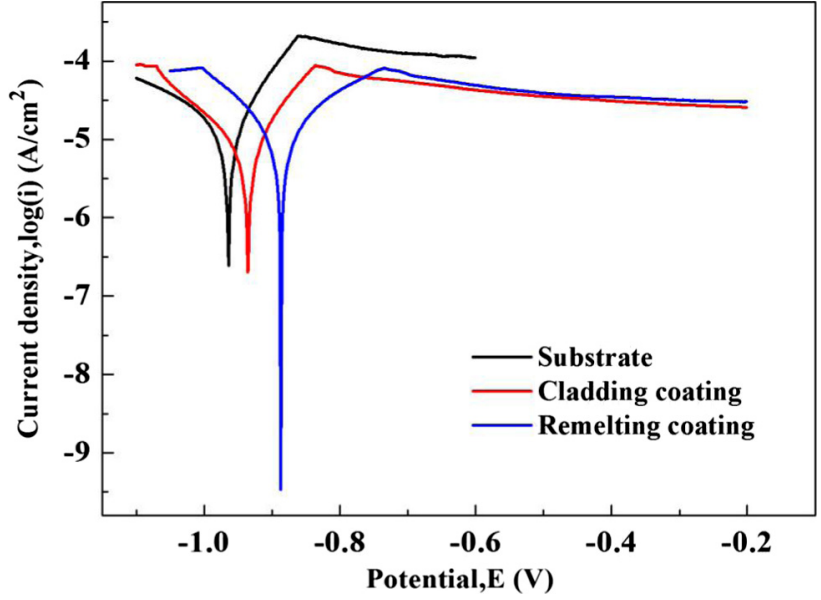

Fig. 8. Potentiodynamic polarization curves of composite coatings and substrate in 3.5 wt.\% $\mathrm{NaCl}$ solution.

of the remelting coating is larger than that of the cladding coating. The Bode patterns are composed of three parts (Fig. 10): the first is the lowest frequency area $\left(10^{-2}-10^{0}\right)$ of the maximum $|\mathrm{Z}|$ value,
Table 5

Electrochemical parameters of substrate, cladding and remelting coatings.

\begin{tabular}{llll}
\hline Materials & $\mathrm{E}_{\text {corr }}(\mathrm{V})$ & $\mathrm{I}_{\text {corr }}\left(\mathrm{A} / \mathrm{cm}^{2}\right)$ & $\mathrm{Rp}\left(\Omega \cdot \mathrm{cm}^{2}\right)$ \\
\hline Substrate & -0.964 & $1.76 \times 10^{-5}$ & 1563.3 \\
Cladding coating & -0.936 & $1.47 \times 10^{-5}$ & 2424.2 \\
Remelting coating & -0.884 & $1.25 \times 10^{-5}$ & 2545.8 \\
\hline
\end{tabular}

the second is the middle frequency area $\left(10^{0}-10^{3}\right)$ of the slope of the curves which is close to -1 , and the third is the highest frequency area $\left(10^{3}-10^{4}\right)$ with the lowest $|\mathrm{Z}|$ value which is almost unchanged. Therefore, the diameter and $|Z|$ value in the lowest region of the remelting coating are larger than those of the cladding coating and substrate, resulting in better corrosion resistance of the remelting coating. This is consistent with the results of polarization curves (Fig. 8) and the similar observation was also reported by Fan et al. [46].

As well known, the addition of $\mathrm{Cr}$, Mo or $\mathrm{W}$ can improve the corrosion resistance of amorphous coatings [33]. For example, Farmer et al. $[47,48]$ proposed the formula of PREN (pitting resistance equivalence number) that can be used to evaluate the corrosion resistance of alloys and amorphous coatings. They found that the 


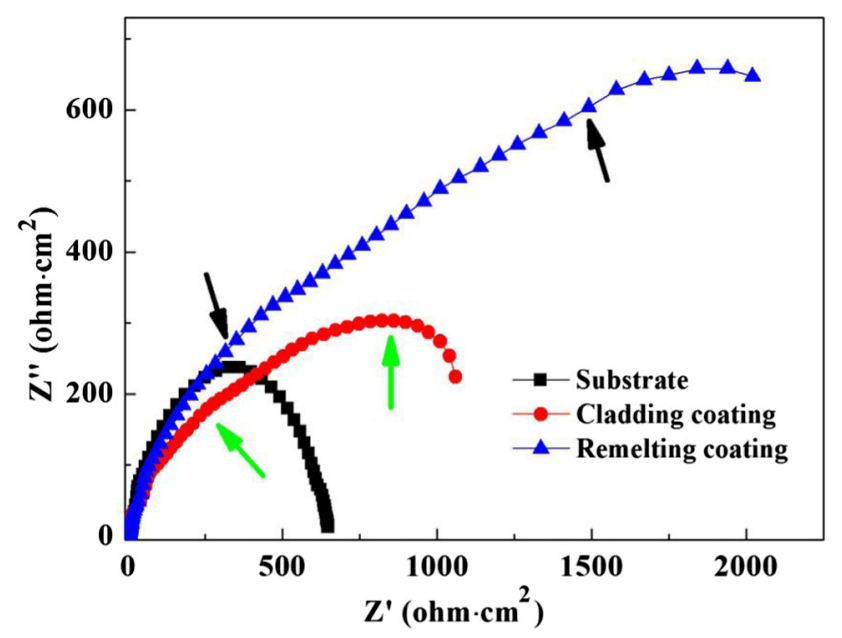

Fig. 9. Nyquist plots of composite coatings and substrate in $3.5 \mathrm{wt} . \% \mathrm{NaCl}$ solution.

pitting resistance of the amorphous coatings was better than that of the alloys, indicating that the stability of passivation films was not only related to chemical composition, but also related to amorphous microstructure. The corrosion resistance of the remelting coating is relatively higher than that of the cladding coating and the substrate (Figs. 8-10), which can be explained by the following reasons: the coating is susceptible to suffer from local etching in $3.5 \mathrm{wt} . \% \mathrm{NaCl}$ solution, so that Fe atoms are dissolved preferentially when the $\mathrm{Cl}$ ions in the electrolyte contact with the coating. Because large amount of crystalline phases containing $\mathrm{Cr}$ and $\mathrm{Mo}$ are formed in the remelting coating, $\mathrm{Cr}$ element is oxidized to form a $\mathrm{Cr}$-rich passivation film, which can hinder the erosion of $\mathrm{Cl}$ ions and therefore reduce the corrosion rate of the remelting coating $[49,50]$. Meanwhile, the Mo element can also form the oxide of Mo, which can reduce the dissolution of $\mathrm{Cr}$ in the electrolyte $[51,52]$. Therefore, the passivation potential of the remelting coating remains stable. Wang et al. [53] also found the similar local corrosion of Fe-based amorphous glasses and anodic dissolution processes caused by $\mathrm{Cl}$ ions in the electrolyte. Furthermore, the $\mathrm{Fe}_{23} \mathrm{~B}_{6}$ phase can reduce the passive current density of the remelting coating and the amorphous phase III can also enhance the corrosion resistance. Therefore, the corrosion resistance of the remelting coating is relatively higher than that of the cladding coating.

\subsection{Microhardness of coatings}

Fig. 12 shows microhardness profiles of the cladding and remelting coatings. The average microhardness of the cladding coating is $754 \mathrm{HV}$, which is approximately 3.8 times higher than that of the substrate (197 HV). While the average microhardness of the remelting coating is 4.3 times higher that of the substrate and the maximum value is up to $954 \mathrm{HV}$. This is because large amounts of crystalline phases are formed at the top of the coatings, while the amounts of the crystalline phases decreases and the amounts of amorphous phase increase at the center and bottom of the coatings. As a result, the microhardness at the center of the coatings is relatively higher. Moreover, the addition of $\mathrm{Cr}$ can also enhance the hardness of the composite coatings due to supersaturated solid solution. Comparatively, the microstructure of the remelting coating is finer and many $\gamma$-Fe and $\mathrm{Cr}_{9.1} \mathrm{Si}_{0.9}$ phases are formed in the remelting coating (Figs. 3 and 4). Additionally, large amounts of amorphous phase appear at the center and bottom of the remelting coating. As a result, the microhardness of the remelting coating is approximately 1.13 times higher than that of the cladding coating due to the combination of fine-grain strengthening and solid solution strengthening as well as the formation of amorphous phase.

\section{Conclusions}

The WC-reinforced Fe-based amorphous composite coatings are prepared by laser cladding with rectangle spot and subsequently are performed by laser remelting. The geometrical profiles, microstructure and properties of the cladding and remelting coatings are investigated. The results are listed as follows:

(1) There are pores and microcracks in the cladding coating. On the contrary, there are no cracks and pores in the remelting coating and the surface of the remelting coating becomes smooth.

(2) The planar growth with a thickness of $\sim 3 \mu \mathrm{m}$ is formed and large amounts of white carbides are precipitated at the bottom of the cladding coating. However, new phase $\mathrm{Cr}_{9.1} \mathrm{Si}_{0.9}$ is precipitated in the remelting coating and the microstructure at the top of the remelting coating is finer because of a higher cooling rate during laser remelting.

(3) Large amounts of precipitations rich in $\mathrm{Cr}$ and $\mathrm{Mo}$, the formation of $\mathrm{Fe}_{23} \mathrm{~B}_{6}$ phase as well as the amorphous phase in the remelting coating can form a passivation film in 3.5
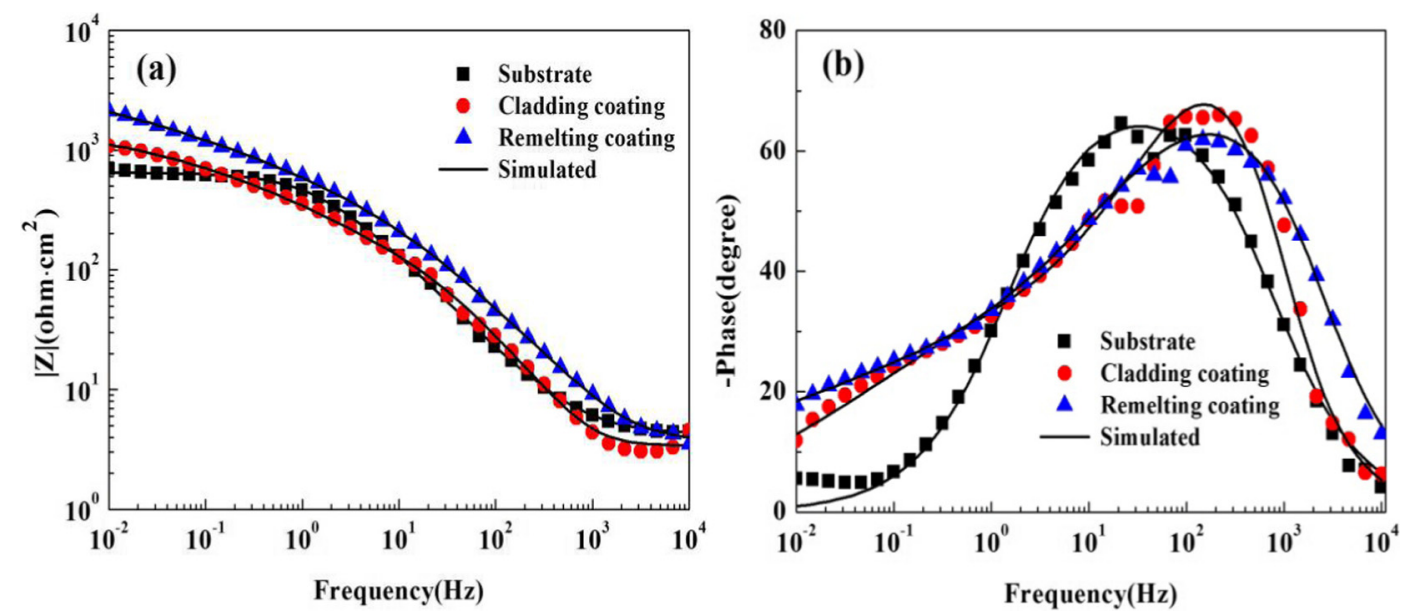

Fig. 10. Bode images of composite coatings and substrate in $3.5 \mathrm{wt} . \% \mathrm{NaCl}$ solution: (a) Bode impedance magnitude curves, (b) Bode phase angle curves. 


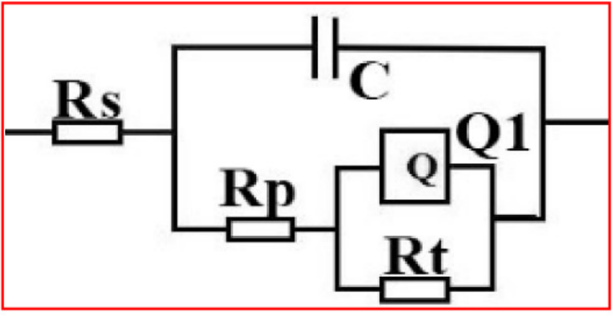

(a)

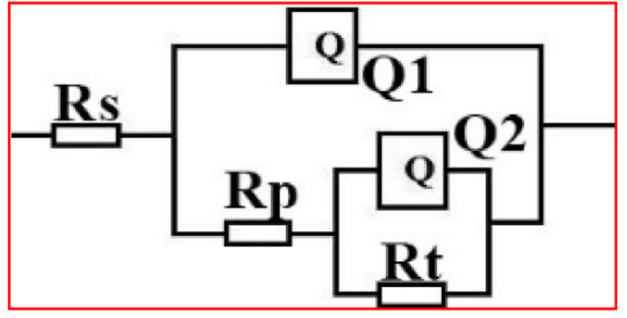

(b)

Fig. 11. Equivalent circuits of composite coatings: (a) cladding coating, (b) remelting coating.

Table 6

Electrochemical parameters obtained from equivalent circuits fitting of composite coatings in $3.5 \mathrm{wt} . \% \mathrm{NaCl}$ solution.

\begin{tabular}{|c|c|c|c|c|c|c|c|c|c|}
\hline Sample & $\mathrm{R}_{\mathrm{s}}\left(\Omega \mathrm{cm}^{2}\right)$ & $\mathrm{R}_{\mathrm{p}}\left(\Omega \mathrm{cm}^{2}\right)$ & $\mathrm{R}_{\mathrm{t}}\left(\Omega \mathrm{cm}^{2}\right)$ & $\mathrm{Q}_{1}-\mathrm{Y}_{\mathrm{o}}\left(\Omega^{-1} \mathrm{~cm}^{-2} \mathrm{~s}^{\mathrm{n}}\right)$ & $\mathrm{n}_{1}$ & $\mathrm{Q}_{2}-\mathrm{Y}_{\mathrm{o}}\left(\Omega^{-1} \mathrm{~cm}^{-2} \mathrm{~s}^{\mathrm{n}}\right)$ & $\mathrm{n}_{2}$ & $\mathrm{C}\left(\mathrm{F} \mathrm{cm}^{-2}\right)$ & $\chi^{2}$ \\
\hline 1 & 3.402 & 4.467 & 1528 & $1.2 \times 10^{-3}$ & 0.44 & - & - & $5.1 \times 10^{-5}$ & $5.4 \times 10^{-3}$ \\
\hline 2 & 3.051 & 0.615 & 5207 & $7.4 \times 10^{-4}$ & 0.33 & $6.23 \times 10^{-5}$ & 0.87 & - & $1.9 \times 10^{-3}$ \\
\hline
\end{tabular}

Note: 1 Refer to cladding coating; 2 Refer to remelting coating.

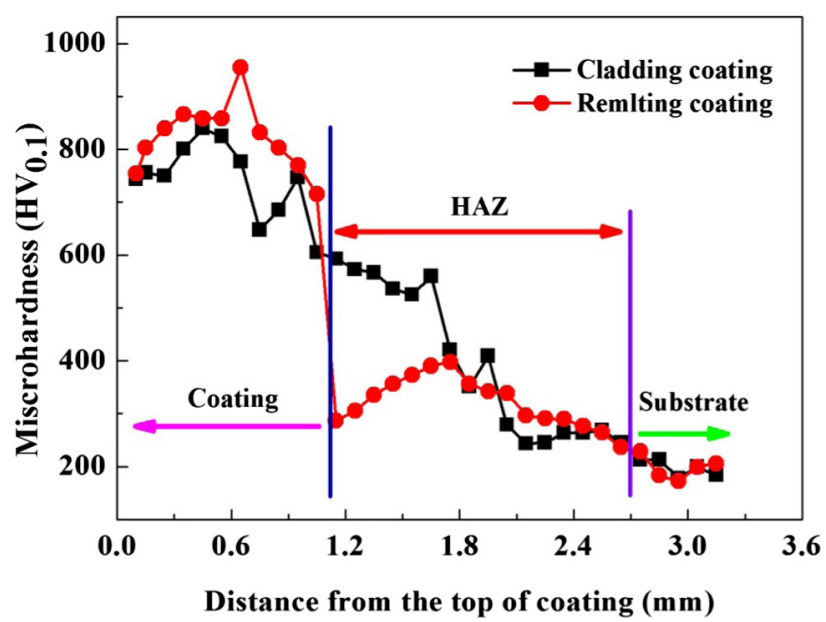

Fig. 12. Microhardness distribution of composite coatings.

wt.\% $\mathrm{NaCl}$ solution, which can reduce the corrosion rate and therefore increase the corrosion resistance of the remelting coating.

(4) The microhardness of the remelting coating is relatively higher than that of the cladding coating and substrate due to the formation of large amounts of amorphous phase and hard strengthening phases.

\section{Acknowledgements}

This work was financially supported by the National Natural Science Foundation of China (Grant No. 50901040) and the Outstanding Youth Foundation of Jiangxi Province (20162BCB23039).

\section{Appendix A. Supplementary material}

Supplementary data associated with this article can be found, in the online version, at https://doi.org/10.1016/j.optlastec.2018.01. 024.

\section{References}

[1] W.H. Wang, The nature and properties of amorphous matter, Progress Phys. 33 (2013) 171-351.
[2] J. Kramer, H. Zahn, Nichtleitende metallmodifikationen, Naturwissenschaften 411 (1934), 792-792.

[3] A. Brenner, D.E. Couch, E.K. Williams, Electrodeposition of alloys of phosphorus with nickel or cobalt, J. Res. Nat. Bur. Stand. 44 (1950), 109-109.

[4] W. Klement, R.H. Willens, P. Duwez, Non-crystalline structure in solidified gold-silicon alloys, Nature 187 (1960) 869-870.

[5] H.S. Chen, C.E. Miller, A rapid quenching technique for the preparation of thin uniform films of amorphous solids, Rev. Sci. Instrum. 41 (1970) 1237-1238.

[6] L.C. Zhang, Z.O. Shen, J. Xu, Mechanically milling-induced amorphization in Sncontaining Ti-based multicomponent alloy systems, Mater. Sci. Eng., A 394 (2005) 204-209.

[7] L.C. Zhang, K.B. Kim, P. Yu, W.Y. Zhang, U. Kunz, J. Eckert, Amorphization in mechanically alloyed ( $\mathrm{Ti}, \mathrm{Zr}, \mathrm{Nb})-(\mathrm{Cu}, \mathrm{Ni})$-Al equiatomic alloys, J. Alloy. Compd. 428 (2007) 157-163.

[8] L.C. Zhang, J. Xu, E. Ma, Mechanically alloyed amorphous $\mathrm{Ti}_{50}\left(\mathrm{Cu}_{0.45} \mathrm{Ni}_{0.55}\right)_{44-x} \mathrm{Al}_{x} \mathrm{Si}_{4} \mathrm{~B}_{2}$ alloys with supercooled liquid region, J. Mater. Res. 17 (2002) 1743-1749.

[9] L.C. Zhang, J. Xu, Glass-forming ability of melt-spun multicomponent (Ti, Zr, Hf)-(Cu, Ni, Co)-Al alloys with equiatomic substitution, J. Non-Cryst. Solids 347 (2004) 166-172.

[10] M. Calin, L.C. Zhang, J. Eckert, Tailoring of microstructure and mechanical properties of a Ti-based bulk metallic glass-forming alloy, Scripta Mater. 57 (2007) 1101-1104.

[11] Z. Jia, W.C. Zhang, W.M. Wang, D. Habibi, L.C. Zhang, Amorphous $\mathrm{Fe}_{78} \mathrm{Si}_{9} \mathrm{~B}_{13}$ alloy: An efficient and reusable photo-enhanced Fenton-like catalyst in degradation of cibacron brilliant red 3B-A dye under UV-vis light, Appl. Catal. B 192 (2016) 46-56.

[12] L. Liu, C. Zhang, Fe-based amorphous coatings: Structures and properties, Thin Solid Films 561 (2014) 70-86.

[13] Y. Gao, M. Jie, Y. Liu, Mechanical properties of $\mathrm{Al}_{2} \mathrm{O}_{3}$ ceramic coatings prepared by plasma spraying on magnesium alloy, Surf. Coat. Technol. 315 (2017) 214 219.

[14] J. Jayaraj, D.J. Sordelet, D.H. Kim, Y.C. Kim, E. Fleury, Corrosion behaviour of NiZr-Ti-Si-Sn amorphous plasma spray coating, Corros. Sci. 48 (2006) 950-964.

[15] Z. Zhou, L. Wang, F.C. Wang, H.F. Zhang, Y.B. Liu, S.H. Xu, Formation and corrosion behavior of Fe-based amorphous metallic coatings by HVOF thermal spraying, Surf. Coat. Technol. 204 (2009) 563-570.

[16] S.D. Zhang, J. Wu, W.B. Qi, J.Q. Wang, Effect of porosity defects on the longterm corrosion behaviour of Fe-based amorphous alloy coated mild steel, Corros. Sci. 110 (2016) 57-70.

[17] Y.B. Cao, H.T. Ren, C.S. Hu, Q.X. Meng, Q. Liu, In-situ formation behavior of NbCreinforced Fe-based laser cladding coatings, Mater. Lett. 147 (2015) 61-63.

[18] Y.Y. Zhu, Z.G. Li, R.F. Li, M. Li, X.L. Daze, K. Feng, Y.X. Wu, Microstructure and property of Fe-Co-B-Si-C-Nb amorphous composite coating fabricated by laser cladding process, Appl. Surf. Sci. 280 (2013) 50-54.

[19] X. Wu, B. Xu, Y. Hong, Synthesis of thick $\mathrm{Ni}_{66} \mathrm{Cr}_{5} \mathrm{Mo}_{4} \mathrm{Zr}_{6} \mathrm{P}_{15} \mathrm{~B}_{4}$ amorphous alloy coating and large glass-forming ability by laser cladding, Mater. Lett. 56 (2002) $838-841$.

[20] M. Iqbal, J.I. Akhter, Influence of Y and $\mathrm{Nb}$ addition on crystallization behavior and mechanical properties of $\mathrm{Zr}-\mathrm{Ni}-\mathrm{Al}-\mathrm{Cu}-\mathrm{M}$ bulk amorphous alloys, Adv. Mater. Res. 326 (2011) 11-18.

[21] A. Inoue, T. Masumoto, Mg-based amorphous alloys, Mater. Sci. Eng., A 173 (1993) $1-8$.

[22] U. Köster, U. Herold, H.-G. Hillenbrand, J. Denis, Diffusion in some iron-based metallic glasses, J. Mater. Sci. 15 (1980) 2125-2128.

[23] X. Dai, S. Zhou, M. Wang, J. Lei, C. Wang, T. Wang, Microstructure evolution of phase separated $\mathrm{Fe}-\mathrm{Cu}-\mathrm{Cr}-\mathrm{C}$ coatings by laser induction hybrid cladding, Surf, Coat. Technol. 324 (2017) 518-525. 
[24] H. Yoshioka, K. Asami, A. Kawashima, K. Hashimoto, Laser-processed corrosion-resistant amorphous NiCrPB surface alloys on a mild steel, Cheminform 18 (1987) 981-995.

[25] X. Wu, Y. Hong, Fe-based thick amorphous-alloy coating by laser cladding, Surf. Coat. Technol. 141 (2001) 141-144.

[26] R. Li, Z. Li, J. Huang, Y. Zhu, Dilution effect on the formation of amorphous phase in the laser cladded $\mathrm{Ni}-\mathrm{Fe}-\mathrm{B}-\mathrm{Si}-\mathrm{Nb}$ coatings after laser remelting process, Appl. Surf. Sci. 258 (2012) 7956-7961.

[27] P. Xu, C. Zhang, W. Wang, L. Liu, Pitting mechanism in a stainless steelreinforced Fe-based amorphous coating, Electrochim. Acta 206 (2016) 61-69.

[28] S. Yoon, J. Kim, B.D. Kim, C. Lee, Tribological behavior of $\mathrm{B}_{4} \mathrm{C}$ reinforced Fe-base bulk metallic glass composite coating, Surf. Coat. Technol. 205 (2010) 19621968.

[29] T.M. Yue, Y.P. Su, Laser cladding of $\mathrm{SiC}$ reinforced $\mathrm{Zr}_{65} \mathrm{Al}_{7.5} \mathrm{Ni}_{10} \mathrm{Cu}_{17.5}$ amorphous coating on magnesium substrate, Appl. Surf. Sci. 255 (2008) $1692-1698$.

[30] W. Gao, S. Zhao, Y. Wang, F. Liu, C. Zhou, X. Lin, Effect of re-melting on the cladding coating of Fe-based composite powder, Mater. Des. 64 (2014) 490496.

[31] Y. Zhang, X. Lin, L. Wang, L. Wei, F. Liu, W. Huang, Microstructural analysis of $\mathrm{Zr}_{55} \mathrm{Cu}_{30} \mathrm{Al}_{10} \mathrm{Ni}_{5}$ bulk metallic glasses by laser surface remelting and laser solid forming, Intermetallics 66 (2015) 22-30.

[32] Q.Y. Wang, Y.C. Xi, Y.H. Zhao, S. Liu, S.L. Bai, Z.D. Liu, Effects of laser re-melting and annealing on microstructure, mechanical property and corrosion resistance of Fe-based amorphous/crystalline composite coating, Mater. Charact. 127 (2017) 239-247.

[33] R. Li, Y. Jin, Z. Li, Y. Zhu, M. Wu, Effect of the remelting scanning speed on the amorphous forming ability of Ni-based alloy using laser cladding plus a laser remelting process, Surf. Coat. Technol. 259 (2014) 725-731.

[34] K. Chokethawai, D.G. Mccartney, P.H. Shipway, Microstructure evolution and thermal stability of an Fe-based amorphous alloy powder and thermally sprayed coatings, J. Alloy. Compd. 480 (2009) 351-359.

[35] R. Li, Z. Li, J. Huang, P. Zhang, Y. Zhu, Effect of Ni-to-Fe ratio on structure and properties of $\mathrm{Ni}-\mathrm{Fe}-\mathrm{B}-\mathrm{Si}-\mathrm{Nb}$ coatings fabricated by laser processing, Appl. Surf. Sci. 257 (2011) 3554-3557.

[36] W.P. Tian, H.W. Yang, S.D. Zhang, Synergistic effect of Mo, W, Mn and Cr on the passivation behavior of a Fe-Based amorphous alloy coating, Acta Metall. Sin. (2017) $1-13$.

[37] J.M. Pelletier, L. Renaud, F. Fouquet, Solidification microstructures induced by laser surface alloying: influence of the substrate, Mater. Sci. Eng., A 134 (1991) $1283-1287$.

[38] J. Zhang, X. Cui, Y. Yang, Y. Wang, Solidification of the Cu-35 wt pct Fe alloys with liquid separation, Metall. Mater. Trans. A 44 (2013) 5544-5548.
[39] C.P. Paul, H. Alemohammad, E. Toyserkani, A. Khajepour, S. Corbin, Cladding of WC-12Co on low carbon steel using a pulsed Nd:YAG laser, Mater. Sci. Eng., A 464 (2007) 170-176.

[40] S.S. Babu, S.A. David, R.P. Martukanitz, K.D. Parks, Toward prediction of microstructural evolution during laser surface alloying, Metall. Mater. Trans. A 33 (2002) 1189-1200.

[41] W.J. Chou, G.P. Yu, J.H. Huang, Corrosion behavior of TiN-coated 304 stainless steel, Corros. Sci. 43 (2001) 2023-2035.

[42] R.Q. Guo, C. Zhang, Q. Chen, Y. Yang, N. Li, L. Liu, Study of structure and corrosion resistance of Fe-based amorphous coatings prepared by HVAF and HVOF, Corros. Sci. 53 (2011) 2351-2356.

[43] R. Hang, S. Ma, V. Ji, P.K. Chu, Corrosion behavior of NiTi alloy in fetal bovine serum, Electrochim. Acta 55 (2010) 5551-5560.

[44] J. Jiao, Q. Luo, X. Wei, Y. Wang, J. Shen, Influence of sealing treatment on the corrosion resistance of Fe-based amorphous coatings in $\mathrm{HCl}$ solution, J. Alloy. Compd. 714 (2017) 356-362.

[45] W.R. Osório, E.S. Freitas, A. Garcia, EIS and potentiodynamic polarization studies on immiscible monotectic Al-In alloys, Electrochim. Acta 102 (2013) 436-445.

[46] H.B. Fan, W. Zheng, G.Y. Wang, P.K. Liaw, J. Shen, Corrosion behavior of $\mathrm{Fe}_{41} \mathrm{Co}_{7} \mathrm{Cr}_{15} \mathrm{Mo}_{14} \mathrm{C}_{15} \mathrm{~B}_{6} \mathrm{Y}_{2}$ bulk metallic glass in sulfuric acid solutions, Metall. Mater. Trans. A 42 (2011) 1524-1533.

[47] J.C. Farmer, J.S. Choi, C.K. Saw, R. Rebak, S.D. Day, T. Lian, P. Hailey, J.H. Payer, D J. Branagan, L.F. Aprigliano, Corrosion resistance of amorphous $\mathrm{Fe}_{49.7} \mathrm{Cr}_{17.7} \mathrm{Mn}_{1.9} \mathrm{Mo}_{7.4} \mathrm{~W}_{1.6} \mathrm{~B}_{15.2} \mathrm{C}_{3.8} \mathrm{Si}_{2.4}$ coating-a new criticality-controlled material, Off. Sci. Tech. Inform. Tech. Rep. 161 (2007) 169-189.

[48] J.C. Farmer, J.J. Haslam, S.D. Day, T. Lian, C.K. Saw, P.D. Hailey, J.S. Choi, R.B Rebak, Corrosion resistance of thermally sprayed high-boron iron-based amorphous-metal coatings: $\mathrm{Fe}_{49.7} \mathrm{Cr}_{17.7} \mathrm{Mn}_{1.9} \mathrm{Mo}_{7.4} \mathrm{~W}_{1.6} \mathrm{~B}_{15.2} \mathrm{C}_{3.8} \mathrm{Si}_{2.4}$, J. Mater Res. 22 (2007) 2297-2311.

[49] N. Dai, L.C. Zhang, J. Zhang, X. Zhang, Q. Ni, Y. Chen, M. Wu, C. Yang, Distinction in corrosion resistance of selective laser melted Ti-6Al-4V alloy on different planes, Corros. Sci. 111 (2016) 703-710.

[50] N. Dai, L.C. Zhang, J. Zhang, X. Zhang, Q. Chen, M. Wu, Corrosion behavior of selective laser melted Ti-6Al-4V alloy in $\mathrm{NaCl}$ solution, Corros. Sci. 102 (2016) 484-489.

[51] L. Wang, Y. Chao, Corrosion behavior of $\mathrm{Fe}_{41} \mathrm{Co}_{7} \mathrm{Cr}_{15} \mathrm{Mo}_{14} \mathrm{C}_{15} \mathrm{~B}_{6} \mathrm{Y}_{2}$ bulk metallic glass in $\mathrm{NaCl}$ solution, Mater. Lett. 69 (2012) 76-78.

[52] S.F. Guo, K.C. Chan, S.H. Xie, P. Yu, Y.J. Huang, H.J. Zhang, Novel centimetersized Fe-based bulk metallic glass with high corrosion resistance in simulated acid rain and seawater, J. Non-Cryst. Solids 369 (2013) 29-33.

[53] Y. Wang, S.L. Jiang, Y.G. Zheng, W. Ke, W.H. Sun, J.Q. Wang, Electrochemical behaviour of Fe-based metallic glasses in acidic and neutral solutions, Corros. Sci. 63 (2012) 159-173. 